\title{
Gluten-free food issues in Turkey
}

\author{
Guler ATASOY $^{1 \star}$ (D), Ozge Kurt GOKHISAR ${ }^{1}$ (D), Mahir TURHAN ${ }^{1}$
}

\begin{abstract}
Consumption of gluten-free foods (GFFs), natural GFFs (nGFFs) or manufactured GFFs (mGFFs), is reported as a burden on GFF-consumers for different countries. In Turkey, only mGFFs are recognized to be GF, and issues related to them were investigated for the first time. Accessibility of mGFFs is too restricted. Celiac, not other gluten-linked diseases, is recognized in the institutional practices. Price of mGFFs is 5.5 times on average more expensive than corresponding gluten containing foods (cGCFs). GFF-consumers in Turkey are under a heavy burden of the high price pressure, and it is more than the burden on GFF-consumers in other countries not considering the economic welfare difference. Though, imported mGFFs are more expensive than domestic mGFFs, imported ones dominate the market. Well-established arrangements are needed for easing the burden on $\mathrm{mGFF}$-consumers in the country. The lowest possible expenditure for mGFFs by celiac population is almost $\$ 649 \times 10^{6}$ per year excluding individuals with other gluten-linked disorders. Turkey is quite untouched market and offers lucrative business opportunities for mGFFs.
\end{abstract}

Keywords: gluten; gluten-free food; gluten-linked disorder; celiac.

Practical Application: Gluten-free nutrition has its own hardships. Some gluten-free food issues are common in all countries such as disturbingly high prices, and some are country specific. This work is the first one, to the best knowledge of the authors, reporting gluten-free food issues in Turkey for the attention of national and international parties. Institutional practices related to gluten-free foods need to be amended, and more institutional populist practices are needed.

\section{Introduction}

Gluten-free foods (GFFs) are either consumed by individuals for having at least one gluten-linked disorder, or by individuals for any reason other than a gluten-linked disorder. Based upon the reason of the consumption, GFF-consumers can be grouped to be mandatory GFF-consumers (with at least one gluten-linked disorder) and voluntary GFF-consumers (without any gluten-linked disorder).

The most commonly known gluten-linked disorder is celiac. Its incidence is estimated $1 \%$ for different populations (Bai et al., 2013). The incidence of gluten-linked disorders is estimated as high as $13 \%$ excepting celiac and wheat allergy (Molina-Infante et al., 2015). The rate of voluntary GFF-consumers is estimated to be $25 \%$ in the USA (Mintel, 2015) and 8\% in the EU (Kraushaar, 2015) and they are expected to rise (Mintel, 2016). Consumption of GFFs appears to be related to large populations and its issues deserve a close attention.

Gluten concentration must not be above $20 \mathrm{ppm}$ for a food to be recognized as GF (Codex Standard 118, 1979). GFFs could be classified as naturally GFFs (nGFFs) and manufactured GFFs (mGFFs). nGFFs do not contain gluten by nature, and recipe of foods manufactured using them do not contain gluten. They can be grouped to be fresh nGFFs, such as fruits, vegetables, milk etc., and manufactured nGFFs, such as fruit juice, tomato paste, yoghurt etc. They are produced for ordinary consumption, neither for being GF nor for imitating manufactured gluten containing foods (GCF). They may be supplied into market with the claim of GF. mGFFs are manufactured foods and purposively made for GF-consumption. They are not produced using raw materials purified from gluten as the GF inscription may imply. They are manufactured using GF raw materials for imitating manufactured GCFs, such as bread, pasta etc. They are supplied into market with the claim of GF.

Issues regarding GFF-consumption have been reported for different countries. Some GFF-issues are common, and some are country-specific. The disproportionally high prices of GFFs is a leading and common issue and alone aggravates other GFF-issues in Australia (Lambert \& Ficken, 2016), Canada (Stevens \& Rashid, 2008), Chile (Castillo \& Rivas, 2008), Greece (Panagiotou \& Kontogianni, 2017), UK (Abernethy \& Bannerman, 2011; Singh \& Whelan, 2011), and USA (Burden et al., 2015; Cureton, 2007; Lee et al., 2007).

Though GFF-issues are reported for some countries by highlighting the economic burden, such a report is not available for Turkey yet to the best knowledge of authors. Together with other GFF-issues, the unaffordable prices of mGFFs are rumored to make the life of GFF-consumers significantly complicated in Turkey like in other countries. In Turkey, prices of fresh nGFFs are within the range of average food prices, and in fact only mGFFs are recognized to be GFF and they are considered to be economic burden (Aydoğdu, 2008). The aim of this work is to document GFF-issues for the first time for Turkey from a broad perspective. 


\section{Materials and methods}

mGFFs and gluten containing foods corresponding to them (cGCFs) available in the Turkish market were determined 3 times within 2 weeks at market and internet venues within the years of 2015-2017.

Prices of products were determined in USD/100 g without considering the package size. mGFFs were gathered under 8 categories (pasta, farina, breakfast cereal, cookie, snack, bread, cracker, and traditional). Every category was further divided into appropriate sub-categories (65 in total) based on traits of mGFFs and every category was divided into 2 sections (domestic and imported) (Table 1). cGCFs were collected under the same categories, sub-categories and sections. Independent- test $(\mathrm{p}<0.05)$ was used to examine the difference between groups (SPSS Inc., Chicago, USA).

\section{Results}

\subsection{Supply of mGFFs}

Number of mGFFs and cGCFs available in the Turkish market were determined to be 170 and 390, respectively. Domestic and imported mGFFs were counted as 81 and 89 , respectively. Number of domestic and imported cGCFs was 288 and 102, respectively. Domestic mGFFs were supplied under 20 brands and imported mGFFs were supplied under 12 brands. The number of brands is equal to the number of supplying companies.

Only three domestic private companies manufacture solely mGFFs in Turkey. Two of them are small in size, and one is in size of atelier. The size of other domestic private companies supplying mGFFs are somewhere between small and large. They manufacture mGFFs in minor amounts in addition to their mainstream GCF-production. A couple of big non-profit companies operated by municipalities are in the mGFF-business, too. Similarly, they produce mGFFs in minor amounts in addition to their mainstream GCF-production which is mainly bread.

Bread Plant of Metropolitan Municipality of Istanbul (population $\approx 15000000$ ) is one of the largest mGFF-producers in Turkey. It manufactures a few types of mGFFs (one type of flour, two types of bread and two types of cookie) and supplies them mainly in its kiosks located in some points in the city. They are not available at any time except the GF-flour. Customers have to order them a couple of days in advance the day of the purchase. The plant also supplies the GF-bread and the GF-flour

Table 1. mGFFs and cGCFs available in the Turkish market and their prices (USD/100 g).

\begin{tabular}{|c|c|c|c|c|c|c|c|}
\hline \multirow{3}{*}{ Category } & \multicolumn{4}{|c|}{ mGFFs } & \multicolumn{3}{|c|}{ cGCFs } \\
\hline & \multicolumn{4}{|c|}{$(\mathrm{USD} / 100 \mathrm{~g} \pm \mathrm{SE})$} & \multicolumn{3}{|c|}{$(\mathrm{USD} / 100 \mathrm{~g} \pm \mathrm{SE})$} \\
\hline & Sub-category & Imported mean & Domestic mean & $\begin{array}{c}\text { Sub-category } \\
\text { mean }\end{array}$ & Imported mean & Domestic mean & $\begin{array}{c}\text { Sub-category } \\
\text { mean }\end{array}$ \\
\hline \multirow[t]{7}{*}{ Pasta } & Vermicelli & $1.70 \pm 0.203$ & $0.65 \pm 0.082$ & $1.25 \pm 0.302$ & 0.13 & $0.10 \pm 0.009$ & $0.11 \pm 0.029$ \\
\hline & Spaghetti & $1.10 \pm 0.189$ & $0.72 \pm 0.079$ & $1.00 \pm 0.178$ & $0.41 \pm 0.221$ & $0.10 \pm 0.013$ & $0.21 \pm 0.115$ \\
\hline & Penne & $1.10 \pm 0.180$ & $0.79 \pm 0.308$ & $1.01 \pm 0.171$ & $0.39 \pm 0.217$ & $0.10 \pm 0.008$ & $0.23 \pm 0.138$ \\
\hline & Lasagna & - & $0.70 \pm 0.067$ & $0.70 \pm 0.067$ & $0.55 \pm 0.210$ & $0.49 \pm 0.041$ & $0.53 \pm 0.114$ \\
\hline & Noodle & $0.85 \pm 0.300$ & - & $0.85 \pm 0.300$ & $0.42 \pm 0.063$ & - & $0.42 \pm 0.063$ \\
\hline & Cous cous & $1.29 \pm 0.084$ & $1.54 \pm 0.056$ & $1.38 \pm 0.120$ & 0.60 & $0.10 \pm 0.014$ & $0.13 \pm 0.102$ \\
\hline & Fusilli & $1.09 \pm 0.247$ & $0.84 \pm 0.289$ & $0.96 \pm 0.202$ & $0.38 \pm 0.295$ & $0.11 \pm 0.017$ & $0.17 \pm 0.099$ \\
\hline \multicolumn{2}{|c|}{ Category mean } & $1.24 \pm 0.122$ & $0.81 \pm 0.131$ & $1.17 \pm 0.139$ & $0.41 \pm 0.096$ & $0.38 \pm 0.027$ & $0.23 \pm 0.050$ \\
\hline \multirow[t]{15}{*}{ Farıina } & Flour & - & $0.33 \pm 0.036$ & $0.33 \pm 0.036$ & 0.63 & $0.08 \pm 0.009$ & $0.10 \pm 0.054$ \\
\hline & Bread crumbs & $1.82 \pm 0.450$ & $1.28 \pm 0.062$ & $1.42 \pm 0.251$ & - & $0.28 \pm 0.053$ & $0.28 \pm 0.053$ \\
\hline & Rice flour & - & $0.39 \pm 0.173$ & $0.39 \pm 0.173$ & - & $0.26 \pm 0.059$ & $0.26 \pm 0.059$ \\
\hline & Buckwheat flour & - & $0.53 \pm 0.157$ & $0.53 \pm 0.157$ & - & $0.35 \pm 0.071$ & $0.35 \pm 0.071$ \\
\hline & Corn flour & - & $0.63 \pm 0.157$ & $0.63 \pm 0.157$ & - & $0.19 \pm 0.046$ & $0.19 \pm 0.046$ \\
\hline & Bread mix & $0.84 \pm 0.077$ & $0.52 \pm 0.227$ & $0.77 \pm 0.096$ & - & $0.20 \pm 0.025$ & $0.20 \pm 0.025$ \\
\hline & Cake mix & $0.76 \pm 0.248$ & $0.77 \pm 0.187$ & $0.77 \pm 0.152$ & - & $0.37 \pm 0.129$ & $0.37 \pm 0.129$ \\
\hline & Carb reduced flour & - & 0.90 & 0.90 & - & 0.45 & 0.45 \\
\hline & Potato flour & - & 0.26 & 0.26 & - & - & - \\
\hline & Low protein starchy mix & - & $0.47 \pm 0.085$ & $0.47 \pm 0.085$ & - & - & - \\
\hline & Corn starch & - & $0.27 \pm 0.002$ & $0.27 \pm 0.002$ & - & $0.20 \pm 0.076$ & $0.20 \pm 0.076$ \\
\hline & Dry yeast & - & $1.47 \pm 0.200$ & $1.47 \pm 0.200$ & - & $0.54 \pm 0.214$ & $0.54 \pm 0.214$ \\
\hline & Maize semolina & - & $0.46 \pm 0.151$ & $0.46 \pm 0.151$ & 0.53 & $0.10 \pm 0.015$ & $0.14 \pm 0.117$ \\
\hline & Cracked maize & - & $0.75 \pm 0.440$ & $0.75 \pm 0.440$ & - & $0.10 \pm 0.015$ & $0.10 \pm 0.015$ \\
\hline & Baking powder & - & $0.88 \pm 0.208$ & $0.88 \pm 0.208$ & - & $0.53 \pm 0.120$ & $0.53 \pm 0.120$ \\
\hline \multicolumn{2}{|c|}{ Category mean } & $0.88 \pm 0.132$ & $0.56 \pm 0.092$ & $0.65 \pm 0.083$ & $0.58 \pm 0.161$ & $0.24 \pm 0.046$ & $0.25 \pm 0.047$ \\
\hline \multirow{3}{*}{$\begin{array}{l}\text { Breakfast } \\
\text { cereal }\end{array}$} & Corn flakes & $2.48 \pm 0.386$ & - & $2.48 \pm 0.386$ & 1.70 & $0.55 \pm 0.060$ & $0.63 \pm 0.251$ \\
\hline & Muesli with fruits & $2.75 \pm 0.138$ & - & $2.75 \pm 0.138$ & $1.53 \pm 0.456$ & $0.51 \pm 0.142$ & $0.87 \pm 0.430$ \\
\hline & Chocolate corn flakes & $2.88 \pm 0.429$ & - & $2.88 \pm 0.429$ & - & $0.51 \pm 0.051$ & $0.51 \pm 0.051$ \\
\hline \multicolumn{2}{|c|}{ Category mean } & $2.71 \pm 0.248$ & $\mathbf{N A}^{6}$ & $2.71 \pm 0.248$ & $1.55 \pm 0.393$ & $0.52 \pm 0.502$ & $0.69 \pm 0.198$ \\
\hline
\end{tabular}

${ }^{1}$ sausage; ${ }^{2}$ soup; ${ }^{3}$ dessert; ${ }^{4}$ dessert; ${ }^{5}$ homemade macaroni; ${ }^{6}$ not available. 
Table 1. Continued...

\begin{tabular}{|c|c|c|c|c|c|c|c|}
\hline \multirow{3}{*}{ Category } & \multicolumn{4}{|c|}{ mGFFs } & \multicolumn{3}{|c|}{ cGCFs } \\
\hline & \multicolumn{4}{|c|}{$(\mathrm{USD} / 100 \mathrm{~g} \pm \mathrm{SE})$} & \multicolumn{3}{|c|}{$(\mathrm{USD} / 100 \mathrm{~g} \pm \mathrm{SE})$} \\
\hline & Sub-category & Imported mean & Domestic mean & $\begin{array}{c}\text { Sub-category } \\
\text { mean }\end{array}$ & Imported mean & Domestic mean & $\begin{array}{c}\text { Sub-category } \\
\text { mean }\end{array}$ \\
\hline \multirow{6}{*}{ Cookie } & Baby biscuits & $3.00 \pm 0.270$ & $0.52 \pm 0.040$ & $1.54 \pm 0.988$ & 1.37 & $0.37 \pm 0.239$ & $0.42 \pm 0.273$ \\
\hline & Chocolate dipped cookies & $3.30 \pm 0.539$ & - & $3.30 \pm 0.539$ & $1.75 \pm 1.519$ & $0.73 \pm 0.049$ & $1.41 \pm 1.145$ \\
\hline & Chocolate chip cookies & $2.67 \pm 0.667$ & 3.96 & $2.75 \pm 0.673$ & $2.26 \pm 0.943$ & $0.33 \pm 0.066$ & $1.03 \pm 0.733$ \\
\hline & $\begin{array}{l}\text { Cookies with cream } \\
\text { filling }\end{array}$ & $3.63 \pm 0.463$ & & $3.63 \pm 0.463$ & 0.82 & $0.32 \pm 0.047$ & $0.41 \pm 0.128$ \\
\hline & $\begin{array}{l}\text { Biscuits rich in fiber, } \\
\text { digestive biscuits }\end{array}$ & $3.03 \pm 0.657$ & - & $3.03 \pm 0.657$ & $0.67 \pm 0.178$ & $0.27 \pm 0.136$ & $0.43 \pm 0.197$ \\
\hline & Sponge cake & 3.94 & - & 3.94 & - & - & - \\
\hline \multicolumn{2}{|c|}{ Category mean } & $3.11 \pm 0.244$ & $0.92 \pm 0.523$ & $2.59 \pm 0.340$ & $1.51 \pm 0.541$ & $0.34 \pm 0.709$ & $0.71 \pm 0.225$ \\
\hline \multirow[t]{8}{*}{ Snack } & Wafers filled with cream & $3.17 \pm 0.234$ & - & $3.17 \pm 0.234$ & $2.01 \pm 1.341$ & $0.55 \pm 0.155$ & $1.06 \pm 0.613$ \\
\hline & Chocolate wafers & $5.09 \pm 0.880$ & - & $5.09 \pm 0.880$ & - & $0.65 \pm 0.094$ & $0.65 \pm 0.094$ \\
\hline & Cupcake with cacao & - & $0.73 \pm 0.145$ & $0.73 \pm 0.145$ & - & $0.44 \pm 0.051$ & $0.44 \pm 0.051$ \\
\hline & Chocolate bar & $7.72 \pm 2.312$ & - & $7.72 \pm 2.312$ & - & $0.60 \pm 0.042$ & $0.60 \pm 0.042$ \\
\hline & Corn-rice snacks & $3.80 \pm 0.397$ & - & $3.80 \pm 0.397$ & - & $0.46 \pm 0.076$ & $0.46 \pm 0.076$ \\
\hline & Chips & - & $2.33 \pm 1.744$ & $2.33 \pm 1.744$ & $1.35 \pm 0.153$ & $0.65 \pm 0.080$ & $0.77 \pm 0.215$ \\
\hline & $\begin{array}{l}\text { Wafer fingers in milk } \\
\text { chocolate }\end{array}$ & $8.26 \pm 0.662$ & - & $8.26 \pm 0.662$ & - & $0.74 \pm 0.049$ & $0.74 \pm 0.049$ \\
\hline & Lemon cake & 3.47 & - & 3.47 & - & $0.30 \pm 0.016$ & $0.30 \pm 0.016$ \\
\hline \multicolumn{2}{|c|}{ Category mean } & $4.76 \pm 0.814$ & $1.11 \pm 0.666$ & $3.99 \pm 0.847$ & $1.88 \pm 1.088$ & $0.58 \pm 0.575$ & $0.75 \pm 0.203$ \\
\hline \multirow[t]{6}{*}{ Cracker } & $\begin{array}{l}\text { Crackes with olives and } \\
\text { tomatoes }\end{array}$ & 5.43 & $1.53 \pm 1.710$ & $2.40 \pm 2.260$ & $1.41 \pm 0.507$ & $0.56 \pm 0.139$ & $0.95 \pm 0.334$ \\
\hline & Salted crackers & $3.20 \pm 0.452$ & - & $3.20 \pm 0.452$ & $1.29 \pm 1.141$ & $0.35 \pm 0.087$ & $0.57 \pm 0.435$ \\
\hline & Grissini & $3.42 \pm 0.544$ & - & $3.42 \pm 0.544$ & $1.66 \pm 0.615$ & $0.63 \pm 0.083$ & $0.74 \pm 0.266$ \\
\hline & Salty sticks & $3.97 \pm 0.033$ & - & $3.97 \pm 0.033$ & 2.87 & $0.21 \pm 0.011$ & $0.39 \pm 0.570$ \\
\hline & Cheesy flavoured biscuits & $3.26 \pm 0.352$ & - & $3.26 \pm 0.352$ & 0.70 & $0.34 \pm 0.090$ & $0.38 \pm 0.164$ \\
\hline & $\begin{array}{l}\text { Grissini and chocolate } \\
\text { sauce }\end{array}$ & $12.67 \pm 2.186$ & - & $12.67 \pm 2.186$ & $2.77 \pm 1.35$ & - & $2.77 \pm 1.35$ \\
\hline \multicolumn{2}{|c|}{ Category mean } & $3.78 \pm 0.783$ & $1.53 \pm 1.713$ & $3.58 \pm 0.764$ & $1.55 \pm 0.475$ & $0.45 \pm 0.799$ & $0.75 \pm .0218$ \\
\hline \multirow[t]{9}{*}{ Traditional } & Chicken mortar & - & $3.33 \pm 0.345$ & $3.33 \pm 0.345$ & - & $1.37 \pm 0.792$ & $1.37 \pm 0.792$ \\
\hline & Soups & - & $4.12 \pm 0.351$ & $4.12 \pm 0.351$ & - & $0.62 \pm 0.053$ & $0.62 \pm 0.053$ \\
\hline & Sucuk $^{1}$ & - & 1.71 & 1.71 & - & 1.84 & 1.84 \\
\hline & Meat ball mixture & - & $3.60 \pm 0.465$ & $3.60 \pm 0.465$ & - & $0.83 \pm 0.224$ & $0.83 \pm 0.224$ \\
\hline & Tarhana $^{2}$ & - & $3.19 \pm 1.373$ & $3.19 \pm 1.373$ & - & $0.62 \pm 0.178$ & $0.62 \pm 0.178$ \\
\hline & Baklava $^{3}$ & - & $2.05 \pm 0.416$ & $2.05 \pm 0.416$ & - & $1.53 \pm 0.325$ & $1.53 \pm 0.325$ \\
\hline & Gullac ${ }^{4}$ & - & $1.60 \pm 0.773$ & $1.60 \pm 0.773$ & - & $0.61 \pm 0.289$ & $0.61 \pm 0.289$ \\
\hline & Eriste $^{5}$ & - & $2.22 \pm 0.163$ & $2.22 \pm 0.163$ & - & $0.37 \pm 0.172$ & $0.37 \pm 0.172$ \\
\hline & Carob spread & - & $1.13 \pm 0.122$ & $1.13 \pm 0.122$ & - & $1.27 \pm 0.455$ & $1.27 \pm 0.455$ \\
\hline \multicolumn{2}{|c|}{ Category mean } & $\mathbf{N A}^{6}$ & $2.79 \pm 0.365$ & $2.79 \pm 0.365$ & - & $0.70 \pm 0.155$ & $0.70 \pm 0.155$ \\
\hline \multicolumn{2}{|c|}{ General mean } & $2.69 \pm 0.247$ & $1.28 \pm 0.201$ & $2.10 \pm 0.183$ & $1.17 \pm 0.253$ & $0.38 \pm 0.037$ & $0.52 \pm 0.062$ \\
\hline
\end{tabular}

${ }^{1}$ sausage; ${ }^{2}$ soup; ${ }^{3}$ dessert; ${ }^{4}$ dessert; ${ }^{5}$ homemade macaroni; ${ }^{6}$ not available. 
over internet nationwide. Similarly, Bread Plant of Metropolitan Municipality of Ankara (population $\approx 5500000$ ) produces and supplies one type of GF-bread and one type of GF-chips in its kiosks in some points in the city. GF-bread should be ordered a couple of days in advance the day of purchase as in case of Istanbul.

Table 2 compares number of mGFFs in each category and the contribution of the category to the total. The farina category has the highest contribution (44 items, 26\%). The following highest contributions are from the pasta category (32 items, $19 \%)$, the cookie category (27 items, $16 \%$ ), and the bread category (17 items, 10\%).

Table 2 also compares number of mGFFs section-wise and the contribution of each section to the category. Comparison in the traditional category was not applicable, since their imported analogues are not available. Only to the farina category, imported mGFFs have lower contribution than domestic mGFFs. It is the lowest contribution of $23 \%$ (10 of 44) among contribution of imported mGFFs to other categories. In all other categories, imported mGFFs have greater contribution than domestic mGFFs ranging from $62.5 \%$ to the pasta category (20 of 32) to $100 \%$ to the breakfast cereal category (4 of 4 ).

\subsection{Institutional practices for mGFFs}

Imported mGFFs are subject to official proof of gluten content of $20 \mathrm{ppm}$ at maximum for entering the Turkish market (Ministry of Food, Agriculture and Livestock of Turkey, 2017b). Such a proof is not looked for domestic mGFFs for entering the market. The supply of nGFFs into the market with the claim of GF is forbidden for both domestic and imported GFFs in the legislation (Turkish Food Codex - Turkey, 2010).

Social Security Institution of Turkey (SSI) subsidizes celiac individuals certified by the Ministry of Health for one year (Social Security Institution of Turkey, 2015a). The certification entails diagnosis report for celiac by a gastroenterologist, if not available by an internist, as the proof. The test and accompanied formalities must be carried out every year to extend the certification one year. The monthly subsidization is based on age. It is $\$ 25$ for the age group of 0 - 5 years, $\$ 37$ for the age group of 5 - 15 years, and \$ 34 for the age group of older than 15 years (Social Security Institution of Turkey, 2015a) averaging \$ 32.

Turkey's population is almost 82000 000, and the celiac population is estimated $1 \%$ as in other countries (Mustalahti et al., 2010; Rubio-Tapia et al., 2012; Turkish Public Health Institution - Turkey, 2018). The celiac population should probably be 820000 in Turkey. The number of certified celiac people is reported to be 40703 by the Ministry of Health (Turkish Public Health Institution - Turkey, 2018). This figure represents a small portion $(4.9 \%)$ of the probable celiac population.

In Turkey, military service is mandatory for every young male citizen with good health. They serve the Military for 12 months. During this period, they live in troop units, and their foods are cooked in garrisons. In garrisons, GFFs are not cooked for individuals with a gluten-linked disorder, and they have to consume GCFs like their peers. In the Turkish Armed Forces Health Regulation (Turkish Armed Forces - Turkey, 2015b) gluten enteropathy (celiac) is taken as a metabolic and not curable disorder, and men with celiac are deemed to be not fit for and exempted from the service.

\subsection{Comparison of prices of $m G F F s$ and $c G C F s$}

Number of prices collected was 851 for 170 mGFFs, and 910 for $390 \mathrm{cGCFs}$ in the market. Prices of mGFFs at market and internet venues were almost same. Average prices of the products in each sub-category are provided in Table 1. Prices of mGFFs and cGCFs were compared category-wise to get an insight into the monetary aspects of the mGFF-consumption (Table 3 ).

Column A in Table 3 compares prices of mGFFs and cGCFs imported into Turkey. The former is more expensive than the latter in all categories as much as 2.3 times on average. Column $\mathrm{B}$ in Table 3 compares prices of all mGFFs and all cGCFs available in the market. mGFFs are more expensive than cGCFs in all categories with average ratio of 4.0. Column $\mathrm{C}$ in Table 3 compares prices of all mGFFs versus domestic cGCFs. mGFFs are more expensive than cGCFs in all categories with average ratio of 5.5. Column D in Table 3 compares prices of imported $\mathrm{mGFF}$ and domestic cGCFs. Imported mGFFs are more expensive than domestic cGCFs in all categories with average ratio of 7.0. Column E in Table 3 compares prices of domestic mGFFs

Table 2. Distribution of mGFFs in the Turkish market.

\begin{tabular}{|c|c|c|c|}
\hline \multirow[t]{2}{*}{ Category } & \multirow{2}{*}{$\begin{array}{c}\text { Number of mGFFs in category and } \\
\text { the contribution of the category to } \\
\text { the total }\end{array}$} & \multicolumn{2}{|c|}{$\begin{array}{l}\text { Number of mGFFs in section and the contribution of the } \\
\text { section to the category }\end{array}$} \\
\hline & & Imported & Domestic \\
\hline Pasta & $32 \& 19 \%$ & $20 \& 62.5 \%$ & $12 \& 37.5 \%$ \\
\hline Breakfast cereal & $4 \& 2 \%$ & $4 \& 100 \%$ & $-\& 0 \%$ \\
\hline Cookie & $27 \& 16 \%$ & $21 \& 78 \%$ & $6 \& 22 \%$ \\
\hline Cracker & $12 \& 7 \%$ & $10 \& 83 \%$ & $2 \& 17 \%$ \\
\hline Traditional & $19 \& 11 \%$ & - \& $0 \%$ & $19 \& 100 \%$ \\
\hline Total & $170 \& 100 \%$ & $89 \& 52 \%$ & $81 \& 48 \%$ \\
\hline
\end{tabular}


Table 3. Ratio of mean prices of mGFFs and cGCFs available in the Turkish market ${ }^{1,2}$.

\begin{tabular}{|c|c|c|c|c|c|c|c|}
\hline \multirow{3}{*}{ Category } & $\mathrm{A}$ & $\mathrm{B}$ & $\mathrm{C}$ & $\mathrm{D}$ & $\mathrm{E}$ & $\mathrm{F}$ & $\mathrm{G}$ \\
\hline & Imp. mGFFs/ & All mGFFs/ & All mGFFs/ & Imp. mGFFs/ & Dom. mGFFs/ & Imp. mGFFs/ & Imp. cGCFs/ \\
\hline & Imp. cGCFs & All cGCFs & Dom. cGCFs & Dom. cGCFs & Dom. cGCFs & Dom. mGFFs & Dom. cGCFs \\
\hline Pasta & 3.0 & 5.1 & 9.0 & 10.5 & 6.9 & 1.5 & 3.5 \\
\hline Farina & 1.5 & 2.6 & 2.7 & 3.7 & 2.3 & 1.6 & 2.4 \\
\hline Breakfast cereal & 1.8 & 3.9 & 5.2 & 5.2 & $\mathrm{NA}^{3}$ & $\mathrm{NA}^{3}$ & 3.0 \\
\hline Cookie & 2.1 & 3.7 & 7.7 & 9.3 & 2.7 & 3.4 & 4.5 \\
\hline Snack & 2.5 & 5.3 & 6.9 & 8.2 & 1.9 & 4.3 & 3.3 \\
\hline Bread & 2.1 & 5.5 & 7.8 & 9.0 & 2.7 & 3.3 & 4.3 \\
\hline Cracker & 2.4 & 4.7 & 8.0 & 8.4 & 3.4 & 2.5 & 3.5 \\
\hline Traditional & NA & 4.0 & 4.0 & $\mathrm{NA}^{4}$ & 4.0 & $\mathrm{NA}^{4}$ & $\mathrm{NA}^{4}$ \\
\hline Mean & 2.3 & 4.0 & 5.5 & 7.0 & 3.4 & 2.1 & 3.0 \\
\hline
\end{tabular}

${ }^{1}$ imp. and dom. stand for "imported" and "domestic," respectively; ${ }^{2} \mathrm{~A}$ numerator and a denominator in a ratio are from significantly different populations (P<0.05); ${ }^{3} \mathrm{No}$ domestic $\mathrm{mGFF}$

is available in the market; ${ }^{4}$ No imported mGFF and cGCF are available in the market.

and domestic cGCFs. Prices of mGFFs are considerably higher than those of cGCFs in all categories with average ratio of 3.4. Column F in Table 3 compares prices of imported mGFFs and domestic mGFFs. In all categories imported mGFFs are more expensive than domestic mGFFs as much as 2.1 on average. Column G in Table 3 compares prices of imported cGCFs and domestic cGCFs. Imported cGCFs are more expensive than domestic cGCFs in all categories as much as 3.0 times on average.

\subsection{Economy of mGFF-consuming in Turkey}

The monetary difference between mGFFs and cGCFs was determined using the average ratio of 5.5 in Column C, Table 3 to get an insight into the economy of the mGFF-consuming.

In Turkey, average household population is 3.6 persons. The monthly average household expenditure is $\$ 945$, and the share of bread and other cereal-based foods in it is $4.5 \%$ (Turkish Statistical Institute - Turkey, 2015c). Accordingly, the expenditure of an average consumer in Turkey for bread and other cereal-based foods, e.g. practically for GCFs is

$\frac{945}{3.6} \times \frac{4.5}{100}=\frac{\$ 12}{(\text { month })(\text { person })}$

However, an mGFF-consumer has to pay the following for their GF version, e.g. practically for mGFFs

$$
12 \times 5.5=\frac{\$ 66}{(\text { month })(\text { person })}
$$

The extra payment for consuming mGFFs is

$66-12=\frac{\$ 54}{(\text { month })(\text { person })}$

which corresponds to $13.3 \%$ of the lowest income in Turkey \$ 404 / month.

In case of benefiting from the subsidization granted by the SSI, the economic burden alleviates to some extent. The beneficiary is supposed to pay $54-32=\frac{\$ 22}{(\text { month })(\text { person })}$

in extra with respect to an average consumer which corresponds to $5.4 \%$ of the lowest income.

The potential monetary input into the Turkish mGFF-market by the probable celiac population ( 820000$)$, whether they benefit from the subsidization or not, is

$66 * 820000 * 12=\frac{\$ 649 \times 10^{6}}{y e a r}$

Taking into account of $4.9 \%$ of the probable celiac community benefiting from the subsidization, the monetary output from the celiac community for consuming mGFF is

$54 \times 820000 \times 12 \times \frac{(100-4.9)}{100}-22 \times 820000 \times 12 \times \frac{4.9}{100}=\frac{\$ 495 \times 10^{6}}{\text { year }}$

The difference between the potential input into the market and output from the probable celiac population is the amount of the subsidization granted by SSI

$649 \times 10^{6}-495 \times 10^{6}=\frac{\$ 154 \times 10^{6}}{\text { year }}$

\section{Discussion}

\subsection{Supply issues}

In the Turkish market, varieties of mGFFs are quite scarce, and their volume is significantly small compared to existed cGCF (170 versus 390), and moreover their accessibility is too restricted in the market venues. Extremely low numbers of markets carry mGFFs, and they spare very limited shelf for mGFFs compared to cGCFs and other foods. The apparent share of 20 domestic companies in the supply of mGFFs is $48 \%$ (81 items of 170), and that of 12 foreign companies is $52 \%$ ( 89 items of 170 ). Domestic (20) and foreign companies (12) constitute $63 \%$ and $37 \%$ of companies (32) operating in the market, respectively. Taking into account the number of mGFFs supplied and companies together, the 
weight of domestic companies in the supply is actually smaller (35\%), and that of foreign companies are higher $(65 \%)$ than the apparent supply figures given ( $48 \%$ and $52 \%$, respectively). The effective supply figures reveal that foreign companies and brands are more effective in the Turkish mGFF-market.

Foreign mGFF-companies in the market are internationally recognized and well equipped companies in the mGFF-business. Domestic small size private companies in Turkey producing solely mGFFs are not able to compete with them. Other domestic companies (profit and non-profit) manufacturing mGFFs are actually capable to compete with them in the market. However, they prefer to keep their focus on their mainstream GCF-production.

The founding purpose of the non-profit municipality companies is to support disadvantageous individuals by providing them with cheaper products. In line with their founding purpose and capability, these establishments may get more involved in the mGFF-business, and can readily increase the variety and volume of mGFFs, and develop practical methods for the accessibility of their products by mGFF-consumers.

The leading share of the farina category (26\%) in total (Table 2) is comprehensible since they are raw materials offering possibility of making wide varieties of mGFFs at home including GF-pasta and GF-bread. GF-pasta and GF-bread are reported the most demanded mGFFs (Giuberti et al., 2015). Their combined share $(29 \%)$ is greater than the share of any category in total (Table 2), and verifies Giuberti et al., 2015. Besides the combined share $(29 \%)$ is comparable with the share of the farina category $(26 \%)$ in Table 2.

The share of imported mGFFs is always remarkably higher than those of domestic mGFFs in all categories except the farina and traditional categories (Table 2). Moreover, there is no domestic mGFF in the category of the breakfast cereal. The shares of imported mGFFs in categories reveal once more the dominancy of imported mGFFs in the market.

Production of mGFFs in the farina category is relatively simple. They can be made in an economic way through elementary unit operations such as grinding, blending etc. They are readily producible by companies with limited capability. Production of mGFFs in the categories of pasta, breakfast cereal, cookie, snack, bread, and cracker are relatively more elaborate. They can not be manufactured by domestic companies as good as imported mGFFs. Accordingly, mGFF-consumers in Turkey are more prone to domestic mGFFs in case of homemade products (farina category: 77\%) (Table 2). They are more inclined to imported mGFFs in case of manufactured products (pasta category: $62.5 \%$, breakfast cereal category: $100 \%$, cookie category: $78 \%$, snack category: $73 \%$, bread category: $76 \%$, cracker category: 83\%) (Table 2).

\subsection{Institutional issues}

In the commerce and custom legislation (Ministry of Food, Agriculture and Livestock of Turkey, 2017b), the proof of being GF is enforced for imported mGFFs, and not for domestic ones for entering the market. The compulsory proof only for imported mGFFs does not necessarily point the concern for the protection of mGFF-consumers. It is as per the legislation ruling proof of the declared trait of the commodity imported. Unexceptionally, all mGFFs, either imported or domestic, bearing the claim of GF is supposed to be subject to the proof for entering the market for protecting $\mathrm{mGFF}$-consumers and for ensuring the fair trade for all companies in the mGFF-business.

The supply of nGFFs into the market with the claim of GF is not permitted in the legislation to hinder unduly value addition (Turkish Food Codex - Turkey, 2010), since they are already GF. These products could readily be contaminated by gluten in fact at any point till reaching customers, and could readily be consumed by mGFF-consumers supposing they are already GF. The concern for the unduly value addition is worthy of commendation for the protection of GFF-consumers. However, it is not effective for obviating the unintentional and unwilling gluten intake by GFF-consumers. The concern could be resolved by regulatory control of prices of nGFFs bearing the claim of GF.

Though celiac is not a curable disorder according to the current knowledge (Bai et al., 2013) celiac individuals are exposed to the accompanied formalities every year to extend the subsidization provided by the SSI (Social Security Institution of Turkey, 2015a) one more year. Despite celiac is incurable, going through the same procedure every year is an extra burden for beneficiaries. The certification could be provided life long, and celiac individuals would experience the formalities just once. The subsidization covers celiac individuals only, not individuals with other gluten-linked disorders, though they are all in the same predicament. Considering other gluten-linked disorders in the coverage of the subsidization would make it more populist and relevant to its meaning.

The official number of celiac individuals benefiting from the subsidization (40 703) is much less than the estimated figure of 820000 in Turkey. The probable celiac population seems not to benefit from the subsidization practically. The huge discrepancy could possibly be due to unawareness of the society for celiac. Determined and perpetual introductory efforts could certainly help the awareness of celiac and other gluten-linked disorders raise, and then increase the number of mandatory GFF-consumers benefiting from the subsidization. It would certainly alleviate the accompanying issues at least for the benefit of mandatory GFF-consumers in the first place.

As for the military service, assuming celiac men are not fit to serve, and exempting them from the service is an implicit way to designate them disabled. Culturally, military service is a sort of prestige and social obligation in Turkey for men. They may readily feel segregated and embarrassed because of being devoid of the military service as well as implicitly recognized to be disabled. Serving the military and being honorably discharged is not possible for a celiac man willing to serve. The voluntary men are supposed to be allowed to service by paying attention to their special diet. Besides, as in the subsidization, individuals with other gluten-linked disorders are not covered in the Regulation (Turkish Armed Forces - Turkey, 2015b). They should consume GCFs cooked in garrisons during the service period. As in the case of the subsidization, for being more inclusive and more relevant to its aim, the Regulation needs amendments extending its coverage for men with other gluten-linked disorders. 
The current institutional practices related to GFFs in Turkey legitimate celiac individuals only, and are restricted by the gluten contamination test for imported mGFFs, the subsidization and the exempting from the military service. Amending current institutional practices and establishing new ones including all individuals with gluten-linked disorder would be a proper implementation.

Recently, a Parliament Research Commission was set up by the Grand National Assembly of Turkey to investigate celiac issues in Turkey for determining actions to be taken (Official Newspaper of Turkey, 2017a). It is a pleasing and promising action but limited to celiac. However, it does not necessarily mean that other gluten linked disorders and voluntary GFF-consuming would not be considered later. The initiation of such an action is invaluable. Though it is not as inclusive as much it should be, better than nothing anyhow.

\subsection{Price issues}

Column A in Table 3 compares prices of imported mGFFs and imported cGCFs. The higher prices of mGFFs than those of cGCFs in all categories are an indicator for foreign markets where mGFFs are more expensive than cGCFs. The average ratio of 2.3 in Column A for Turkey is in line with ratios up to 4.1 reported for in Australia (Lambert \& Ficken, 2016), Canada (Stevens \& Rashid, 2008), Chile (Castillo \& Rivas, 2008), Greece (Panagiotou \& Kontogianni, 2017), UK (Abernethy \& Bannerman, 2011; Singh \& Whelan, 2011), and USA (Burden et al., 2015; Cureton, 2007; Lee et al., 2007). Column B in Table 3 compares prices of all mGFFs and all cGCFs in the Turkish market. More expensive mGFFs than cGCFs in all categories with the average ratio of 4.0 are in agreement with the average figure of 2.3 in Column A, Table 3 and with figures up to 4.1 reported for other markets given above. The agreement between figures in the Turkish and foreign markets shows the common attitude of the markets in regard to the pricing, e.g. mGFFs are more expensive than cGCFs in any case. Column $\mathrm{C}$ in Table 3 compares prices of all mGFFs versus domestic cGCFs. The ratio of $\mathrm{mGFFs} / \mathrm{cGCF}$ got higher compared to Column B in all categories, since the higher prices of imported cGCFs (Table 1) are not included in Column C and the average ratio increased to 5.5. Column $\mathrm{D}$ in Table 3 compares prices of imported mGFFs and domestic cGCFs. The ratio got higher compared to Column $\mathrm{B}$ and $\mathrm{C}$ in all categories, since the lower prices of domestic mGFFs (Table 1) are not considered in Column D. The average ratio in Column D increased to 7.0. Comparison of Column D and C also shows that imported mGFFs are more expensive than domestic mGFFs in all categories. Column E in Table 3 compares prices of domestic mGFFs and domestic cGCFs where the effect of the importation is eliminated. Domestic mGFFs are more expensive than domestic cGCFs in all categories. The average ratio of 3.4 in Column $\mathrm{E}$ is in agreement with the ratios found in this work as 2.3 (Column A, Table 3) and 4.0 (Column B, Table 3) and ratios reported for other markets up to 4.1 given before. The higher prices of mGFFs than those of cGCFs (Table 1), once more appeared in the comparison of domestic products in Column $\mathrm{E}$ as in Column $\mathrm{A}$ and B. It shows the unchanging market attitude that, wherever they originate from, mGFFs are always more expensive than cGCFs in any market. Column F in Table 3 compares prices of imported and domestic mGFFs. In all categories, imported mGFFs are always more expensive than domestic mGFFs. Column B, C, and D in Table 3 altogether implicitly indicate the price increasing effect of importation on mGFFs and the price gap between mGFFs and cGCFs in the market. The comparison in Column F eliminates the effect of being GF, and explicitly shows the price increasing effect of the importation on mGFFs (2.1 on average). Column $\mathrm{G}$ in Table 3 compares prices of imported and domestic cGCFs. Imported cGCFs are always more expensive than domestic ones in all categories. The effect of importation on the price is also observed in Column G for cGCFs as observed for mGFFs in Column F. The comparison in Column G consistently verifies the price increasing effect of the importation on $\mathrm{mGFFs}$ ( 3.0 on average) as observed in Column F (2.1 on average). Column F and G conform with Column B, C, D, and E in Table 3, and exhibit that the importation incurs extra costs such as tariff, import taxes etc. on prices of mGFFs and extra economic burden on mGFF-consumers in Turkey. On the ground of medical obligation, the cost of the importation could readily be waived in favor of mandatory GFF-consumers. It could be a reasonable amendment in the import legislation. The waiver would certainly ease the burden on mandatory GFF-consumers to some extent.

The ratios for $\mathrm{mGFF} / \mathrm{cGCF}$ in Column $\mathrm{C}$ and $\mathrm{E}$ are almost always higher than those in Column A in Table 3. The difference is more dramatic in case of importation is effective (5.5 in Column C versus 2.3 in Column A on average). The comparison shows that the economic burden on mGFF-consumers in Turkey is much heavier than the economic burden on mGFF-consumers in other markets cited before. In fact, the burden is much heavier for mGFF-consumers in Turkey, since the lower economic welfare in Turkey compared to above given countries was not considered in calculations.

Giuberti et al. (2015) reported GF-pasta and GF-bread as the most demanded mGFFs. The higher the demand, the higher the price according to the law of supply (Samuelson, 1989). It is possible to observe the provision of this proposition in Table 3. Ratios in the pasta category are always highest from Column A to $\mathrm{E}$ in Table 3. In other words, mGFFs are always much more expensive than CGCFs compared to other categories both in Turkish and other markets. In case of the bread category, the exaggeration is not this much and the ratios in this category are closer to the average ratios in both Turkish and other markets through Column A to E in Table 3. The possible reason to why prices of mGFFs in the bread category is not as much exorbitant as mGFFs in the pasta category could lie in the hedonic preference of mGFF-consumers. Characteristically, GF-pastas could offer comparatively closer traits and satisfaction of GC-pastas; however, GF-bread could not this much. The lower preference of mGFF-consumers controls prices of GF-bread to some extent.

The law of supply (Samuelson, 1989) also comes in sight in the case of the pasta and farina categories in Column $\mathrm{F}$ in Table 3 which is only related to domestic mGFFs. It is 1.5 and 1.6, respectively. It is between $2.5-4.3$ for other categories (breakfast cereal, cookie, snack, bread, cracker, domestic) which are comparatively higher than the former ones. Domestic mGFFs in the pasta and farina categories are demanded as much as imported 
ones compared to other categories. Then their prices are closer to those of imported mGFFs in these categories. In this case, the preference of mGFF-consumers gets the prices of domestic mGFFs in the pasta and farina categories relatively higher.

Though imported mGFFs are always much more expensive than domestic mGFFs, they are more abundant in the Turkish market. This points that imported mGFFs are more preferred by mGFF-consumers. It can be reasoned to the more variety and hedonic acceptability of imported mGFFs.

Above comparisons in Columns A through $\mathrm{F}$ in Table 3 clearly show that mGFFs are always strikingly more expensive than cGCFs in the Turkish and other markets at all categories. Production and handling costs of mGFFs are inherently higher than those of cGCFs. Moderate higher selling prices for mGFFs due to tangible factors are reasonable and fair. Keeping their selling prices this high by assuming they are scarce and mGFF-consumers are in need of them, is an unethical opportunist approach. The other unethical approach is to present the GF-nutrition as if healthy for expanding the GFF-market without a proof (Reilly, 2016). Consuming nGFFs could be healthy due to their nutrition benefits, not due to being GF. The market-oriented perception of "GFF is better than GCF" does not allow consumers to discern nGFFs from mGFFs, and urge them recognize all GFFs (natural or manufactured) healthy. Though mGFFs are reported not to be healthy (Öhlund et al., 2010; Pember \& Rush, 2016; Wild et al., 2010), exploiting this perception positions mGFFs as premium in the market, and unfairly inflates their prices.

\subsection{Economic issues}

The economic burden on mGFF-consumers in Turkey was determined by comparing prices of all mGFFs with those of domestic cGCFs, namely the average ratio of 5.5 in Column C in Table 3. In other words, the effect of imported cGCFs was not considered for the sake of making a practical estimate. Importing mGFFs into Turkey is due to insufficiencies of domestic mGFFs and a sort of compulsory. Importing cGCFs into Turkey is just for pleasure versatility. In fact, domestic companies can overly cover the need of the Turkish market for cGCFs in quantity and quality, and export them in considerable deal (Turkish Statistical Institute - Turkey, 2017c).

The extra cost for consuming mGFFs comprises a considerable part of the lowest income $(5.4-13.3 \%)$ which is a heavy economic burden for the population making the living with the lowest income. Consuming mGFFs for low-incomers is almost beyond imagination.

The size of the economy of consuming mGFFs in Turkey was estimated on the basis of the probable celiac population of 820000 . The basis does not contain number of other mandatory GFF-consumers and all voluntary GFF-consumers since such statistics is not available for Turkey for the time being. The estimated figures are supposed to be much more, when the current and prospective other mandatory GFF-consumers and voluntary GFF-consumers are taken into account.

The revenue of the market comes from the subsidization $\left(\frac{\$ 154 \times 10^{6}}{\text { year }}\right)$ and from celiac individuals $\left(\frac{\$ 495 \times 10^{6}}{\text { year }}\right)$. Whatever the source of the revenue is, the mGFF-market has potential revenue of $\frac{\$ 649 \times 10^{6}}{\text { year }}$ at minimum. It looks quite remarkable and lucrative figure for entrepreneurs.

\section{Conclusion}

The general medium is uneasy for mGFF-consumers in Turkey as in other countries. The variety and volume of mGFFs are limited and reaching them is restricted. Current institutional practices related to mGFFs recognize celiac individuals only, and they need to be amended, and more institutional populist practices are needed. Prices of mGFFs are always much more expensive than CGCFs in the Turkish and other markets wherever they are produced. Imported mGFFs dominate the Turkish market and they incur additional economic burden on mGFF-consumers in Turkey. Though, imported mGFFs are more preferred than domestic mGFFs. Economic estimates based on the probable celiac population look lucrative, and it is more attractive when other mandatory and voluntary GFF-consumers are regarded. Turkey is a quite untouched market and offers attractive business opportunities in terms of mGFFs.

\section{Acknowledgements}

Authors gratefully acknowledge the support of the Scientific Research Unit, the University of Mersin under the project BAP-2015-TP2-1243.

\section{References}

Abernethy, G., \& Bannerman, E. (2011). Comparison of the cost, choice and availability of a healthy balanced gluten-free diet (GFD) with a standard diet that meet nutrient and food based guidance. The Proceedings of the Nutrition Society, 70(OCE4), 188. http://dx.doi. org/10.1017/S0029665111002394.

Aydoğdu, S. (2008). Social problems of celiac in Turkey. In A. Selimoğlu (Ed.), Çölyak Hastalığı (pp. 180-192). Türkiye: İstanbul Logos Publishing.

Bai, J. C., Fried, M., Corazza, G. R., Schuppan, D., Farthing, M., Catassi, C., Greco, L., Cohen, H., Ciacci, C., Eliakim, R., Fasano, A., González, A., Krabshuis, J. H., \& LeMair, A. (2013). World Gastroenterology Organisation Global Guidelines on Celiac Disease. Journal of Clinical Gastroenterology, 47(2), 121-126. http://dx.doi.org/10.1097/ MCG.0b013e31827a6f83. PMid:23314668.

Burden, M., Mooney, P. D., Blanshard, R. J., White, W. L., CambrayDeakin, D. R., \& Sanders, D. S. (2015). Cost and availability of gluten-free food in the UK: in store and online. Postgraduate Medical Journal, 91(1081), 622-626. http://dx.doi.org/10.1136/ postgradmedj-2015-133395. PMid:26310267.

Castillo, C., \& Rivas, C. C. (2008). Costs of a basic food basket for celiac patients in Chile. Revista Medica de Chile, 136(5), 613-619. PMid:18769809.

Codex Standard 118-1979. (1979). Standard for foods for special dietary use for persons intolerant to gluten - Adopted in 1979-Amendment 1983 and 2015 - Revision 2008.

Cureton, P. (2007). The gluten-free diet: can your patient afford it? Practical Gastroenterology, 8, 75-84.

Giuberti, G., Gallo, A., Cerioli, C., Fortunati, P., \& Masoero, F. (2015). Cooking quality and starch digestibility of gluten free pasta using new 
bean flour. Food Chemistry, 175, 43-49. http://dx.doi.org/10.1016/j. foodchem.2014.11.127. PMid:25577049.

Kraushaar, A. (2015). Pasta, rice and grains, issues and insights: annual report. Mintel.

Lambert, K., \& Ficken, C. (2016). Cost and affordability of a nutritionally balanced gluten-free diet: Is following a gluten-free diet affordable? Nutrition \& Dietetics: the Journal of the Dietitians Association of Australia, 73(1), 36-42. http://dx.doi.org/10.1111/1747-0080.12171.

Lee, A. R., Ng, D. L., Zivin, J., \& Green, P. H. (2007). Economic burden of a gluten-free diet. Journal of Human Nutrition and Dietetics, 20(5), 423-430. http://dx.doi.org/10.1111/j.1365-277X.2007.00763.x. PMid:17845376.

Mintel. (2015). Half of americans think gluten-free diets are a fad while 25\% eat gluten-free foods. Retrieved from http://www.mintel.com/ press-centre/food-and-drink/half-of-americans-think-gluten-freediets-are-a-fad-while-25-eat-gluten-free-foods

Mintel. (2016). Gluten-free foods - US. Retrieved from http://academic. mintel.com/display/748050/\#

Molina-Infante, J., Santolaria, S., Sanders, D. S., \& Fernández-Bañares, F. (2015). Systematic review: noncoeliac gluten sensitivity. Alimentary Pharmacology \& Therapeutics, 41(9), 807-820. http://dx.doi. org/10.1111/apt.13155. PMid:25753138.

Mustalahti, K., Catassi, C., Reunanen, A., Fabiani, E., Heier, M., McMillan, S., Murray, L., Metzger, M. H., Gasparin, M., Bravi, E., Maki, M., \& Coeliac EU Cluster, Project Epidemiology. (2010). The prevalence of celiac disease in Europe: results of a centralized, international mass screening project. Annals of Medicine, 42(8), 587-595. http://dx.doi. org/10.3109/07853890.2010.505931. PMid:21070098.

Öhlund, K., Olsson, C., Hernell, O., \& Öhlund, I. (2010). Dietary shortcomings in children on a gluten-free diet. Journal of Human Nutrition and Dietetics, 23(3), 294-300. http://dx.doi.org/10.1111/ j.1365-277X.2010.01060.x. PMid:20337845.

Panagiotou, S., \& Kontogianni, M. D. (2017). The economic burden of gluten-free products and gluten free diet: a cost estimation analysis in Greece. Journal of Human Nutrition and Dietetics, 30(6), 746-752. http://dx.doi.org/10.1111/jhn.12477. PMid:28480510.

Pember, S., \& Rush, S. E. (2016). Motivation for gluten-free diet adherence among adults with and without a Clinically Diagnosed Gluten-Related Illness. Californian Journal of Health Promotion, 14(2), 68-73. http://dx.doi.org/10.32398/cjhp.v14i2.1876.

Reilly, N. R. (2016). The gluten-free diet: Recognizing fact; fiction and fad. The Journal of Pediatrics, 175, 206-210. http://dx.doi.org/10.1016/j. jpeds.2016.04.014. PMid:27185419.

Rubio-Tapia, A., Ludvigsson, J. F., Brantner, T. L., Murray, J. A., \& Everhart, J. E. (2012). The prevalence of celiac disease in the United
States. The American Journal of Gastroenterology, 107(10), 1538-1545. http://dx.doi.org/10.1038/ajg.2012.219. PMid:22850429.

Samuelson, P. A. (1989). Economics (13rd ed.). New York: Mc Grow Hill Education.

Singh, J., \& Whelan, K. (2011). Limited availability and higher cost of gluten-free foods. Journal of Human Nutrition and Dietetics, 24(5), 479-486. http://dx.doi.org/10.1111/j.1365-277X.2011.01160.x. PMid:21605198.

Stevens, L., \& Rashid, M. (2008). Gluten-free and regular foods: a cost comparison. Canadian Journal of Dietetic Practice and Research: A Publication of Dietitians of Canada = Revue Canadienne de la Pratique et de la Recherche en Dietetique: Une Publication des Dietetistes du Canada, 69(3), 147-150. http://dx.doi.org/10.3148/69.3.2008.147. PMid:18783640.

Turkey. (2010). Turkish food codex food labeling and consumer information regulation. Turkish Armed Forces. Retrieved from https://www.tarim. gov.tr/GKGM/Belgeler/Mevzuat/Talimat/TGK_Gida_Etiketleme_ Tuketici_Bilgilendirme_Yonetmelik_Kilavuzu.pdf

Turkey. (2015a). Communiqué pertaining to the amendment of the health implementation communiqué. Social Security Institution of Turkey. Retrieved from http://www.tkhk.gov.tr/5203_sosyal-guvenlik-kuru

Turkey. (2015b). Health care regulation 2015. Turkish Armed Forces. Retrieved from http://www.tsk.tr/Content/pdf/insan_kaynaklari/ TSK_saglik_yetenegi_yonetmeligi.pdf

Turkey. (2015c). Household consumption expenditure 2015. Turkish Statistical Institute. Retrieved from http://www.tuik.gov.tr/ PreHaberBultenleri.do?id=21580

Turkey. (2017a). Assembly research committee established for celiac. Official Newspaper of Turkey. Retrieved from http://www.resmigazete.gov. tr/eskiler/2017/06/20170617-1.htm

Turkey. (2017b). Control of import commodities subject to inspection by the ministry of food, agriculture and livestock of turkey. Ministry of Food, Agriculture and Livestock of Turkey. Retrieved from http:// www.resmigazete.gov.tr/eskiler/2016/12/20161230M1-5.htm

Turkey. (2017c). Foreign trade statistics. Turkish Statistical Institute. Retrieved from http://www.tuik.gov.tr/PreHaberBultenleri.do?id=24822

Turkey. (2018). Celiac disease and prevalence. Turkish Public Health Institution. Retrieved from https://hsgm.saglik.gov.tr/tr/metabolizmave-colyak/\%C3\%A7\%C3\%B6lyak-ve-g\%C3\%B6r\%C3\%BClmes\%C4\%B1kl\%C4\%B1\%C4\%9F\%C4\%B1.html

Wild, D., Robins, G. G., Burley, V. J., \& Howdle, P. D. (2010). Evidence of high sugar intake, and low fibre and mineral intake, in the glutenfree diet. Alimentary Pharmacology \& Therapeutics, 32(4), 573-581. http://dx.doi.org/10.1111/j.1365-2036.2010.04386.x. PMid:20528829. 